\title{
On solutions of inclusion problems and fixed point problems
}

Yuan Hecai

"Correspondence:

hsyuanhc@yeah.net

School of Mathematics and

Information Science, North China

University of Water Resources and

Electric Power, Zhengzhou, 450011,

China

\begin{abstract}
An inclusion problem and a fixed point problem are investigated based on a hybrid projection method. The strong convergence of the hybrid projection method is obtained in the framework of Hilbert spaces. Variational inequalities and fixed point problems of quasi-nonexpansive mappings are also considered as applications of the main results.
\end{abstract}

MSC: $47 \mathrm{H} 05 ; 47 \mathrm{H} 09 ; 47 \mathrm{~J} 25$

Keywords: nonexpansive mapping; inverse-strongly monotone mapping; maximal monotone operator; fixed point

\section{Introduction and preliminaries}

Splitting methods have recently received much attention due to the fact that many nonlinear problems arising in applied areas such as image recovery, signal processing, and machine learning are mathematically modeled as a nonlinear operator equation and this operator is decomposed as the sum of two nonlinear operators. Splitting methods for linear equations were introduced by Peaceman and Rachford [1] and Douglas and Rachford [2]. Extensions to nonlinear equations in Hilbert spaces were carried out by Kellogg [3] and Lions and Mercier [4]. The central problem is to iteratively find a zero of the sum of two monotone operators $A$ and $B$ in a Hilbert space $H$. In this paper, we consider the problem of finding a solution to the following problem: find an $x$ in the fixed point set of the mapping $S$ such that

$$
x \in(A+B)^{-1}(0)
$$

where $A$ and $B$ are two monotone operators. The problem has been addressed by many authors in view of the applications in image recovery and signal processing; see, for example, [5-9] and the references therein.

Throughout this paper, we always assume that $H$ is a real Hilbert space with the inner product $\langle\cdot, \cdot\rangle$ and norm $\|\cdot\|$, respectively. Let $C$ be a nonempty closed convex subset of $H$ and $P_{C}$ be the metric projection from $H$ onto $C$. Let $S: C \rightarrow C$ be a mapping. In this paper, we use $F(S)$ to denote the fixed point set of $S$; that is, $F(S):=\{x \in C: x=S x\}$.

Recall that $S$ is said to be nonexpansive iff

$$
\|S x-S y\| \leq\|x-y\|, \quad \forall x, y \in C .
$$

(c) 2013 Hecai; licensee Springer. This is an Open Access article distributed under the terms of the Creative Commons Attribution License (http://creativecommons.org/licenses/by/2.0), which permits unrestricted use, distribution, and reproduction in any medium, provided the original work is properly cited. 
If $C$ is a bounded, closed, and convex subset of $H$, then $F(S)$ is not empty, closed, and convex; see [10].

$S$ is said to be quasi-nonexpansive iff $F(S) \neq \emptyset$ and

$$
\|S x-y\| \leq\|x-y\|, \quad \forall x \in C, y \in F(S) .
$$

It is easy to see that nonexpansive mappings are Lipschitz continuous; however, the quasi-nonexpansive mapping is discontinuous on its domain generally. Indeed, the quasinonexpansive mapping is only continuous in its fixed point set.

Let $A: C \rightarrow H$ be a mapping. Recall that $A$ is said to be monotone iff

$$
\langle A x-A y, x-y\rangle \geq 0, \quad \forall x, y \in C .
$$

$A$ is said to be strongly monotone iff there exists a constant $\alpha>0$ such that

$$
\langle A x-A y, x-y\rangle \geq \alpha\|x-y\|^{2}, \quad \forall x, y \in C .
$$

For such a case, $A$ is also said to be $\alpha$-strongly monotone. $A$ is said to be inverse-strongly monotone iff there exists a constant $\alpha>0$ such that

$$
\langle A x-A y, x-y\rangle \geq \alpha\|A x-A y\|^{2}, \quad \forall x, y \in C .
$$

For such a case, $A$ is also said to be $\alpha$-inverse-strongly monotone. Notice that

$$
\alpha\|A x-A y\|^{2} \leq\langle A x-A y, x-y\rangle \leq\|A x-A y\|\|x-y\|
$$

clearly shows that $A$ is $\frac{1}{\alpha}$-Lipschitz continuous.

Recall that the classical variational inequality is to find an $x \in C$ such that

$$
\langle A x, y-x\rangle \geq 0, \quad \forall y \in C .
$$

In this paper, we use $\operatorname{VI}(C, A)$ to denote the solution set of (1.1). It is known that $x^{*} \in C$ is a solution to (1.1) iff $x^{*}$ is a fixed point of the mapping $P_{C}(I-\lambda A)$, where $\lambda>0$ is a constant, $I$ stands for the identity mapping, and $P_{C}$ stands for the metric projection from $H$ onto $C$.

A multivalued operator $T: H \rightarrow 2^{H}$ with the domain $D(T)=\{x \in H: T x \neq \emptyset\}$ and the range $R(T)=\{T x: x \in D(T)\}$ is said to be monotone if for $x_{1} \in D(T), x_{2} \in D(T), y_{1} \in T x_{1}$, and $y_{2} \in T x_{2}$, we have $\left\langle x_{1}-x_{2}, y_{1}-y_{2}\right\rangle \geq 0$. A monotone operator $T$ is said to be maximal if its graph $G(T)=\{(x, y): y \in T x\}$ is not properly contained in the graph of any other monotone operator. Let $I$ denote the identity operator on $H$ and $T: H \rightarrow 2^{H}$ be a maximal monotone operator. Then we can define, for each $\lambda>0$, a nonexpansive single-valued mapping $J_{\lambda}: H \rightarrow H$ by $J_{\lambda}=(I+\lambda T)^{-1}$. It is called the resolvent of $T$. We know that $T^{-1} 0=$ $F\left(J_{\lambda}\right)$ for all $\lambda>0$ and $J_{\lambda}$ is firmly nonexpansive.

The Mann iterative algorithm is efficient to study fixed point problems of nonlinear operators. Recently, many authors have studied the common solution problem, that is, find a point in a solution set and a fixed point (zero) point set of some nonlinear problems; see, for example, [11-30] and the references therein. 
In [11], Kamimura and Takahashi investigated the problem of finding zero points of a maximal monotone operator by considering the following iterative algorithm:

$$
x_{0} \in H, \quad x_{n+1}=\alpha_{n} x_{n}+\left(1-\alpha_{n}\right) J_{\lambda_{n}} x_{n}, \quad n=0,1,2, \ldots,
$$

where $\left\{\alpha_{n}\right\}$ is a sequence in $(0,1),\left\{\lambda_{n}\right\}$ is a positive sequence, $T: H \rightarrow 2^{H}$ is a maximal monotone, and $J_{\lambda_{n}}=\left(I+\lambda_{n} T\right)^{-1}$. They showed that the sequence $\left\{x_{n}\right\}$ generated in (1.2) converges weakly to some $z \in T^{-1}(0)$ provided that the control sequence satisfies some restrictions. Further, using this result, they also investigated the case that $T=\partial f$, where $f$ : $H \rightarrow(-\infty, \infty]$ is a proper lower semicontinuous convex function. Convergence theorems are established in the framework of real Hilbert spaces.

In [12], Takahashi an Toyoda investigated the problem of finding a common solution of the variational inequality problem (1.1) and a fixed point problem involving nonexpansive mappings by considering the following iterative algorithm:

$$
x_{0} \in C, \quad x_{n+1}=\alpha_{n} x_{n}+\left(1-\alpha_{n}\right) S P_{C}\left(x_{n}-\lambda_{n} A x_{n}\right), \quad \forall n \geq 0,
$$

where $\left\{\alpha_{n}\right\}$ is a sequence in $(0,1),\left\{\lambda_{n}\right\}$ is a positive sequence, $S: C \rightarrow C$ is a nonexpansive mapping, and $A: C \rightarrow H$ is an inverse-strongly monotone mapping. They showed that the sequence $\left\{x_{n}\right\}$ generated in (1.3) converges weakly to some $z \in V I(C, A) \cap F(S)$ provided that the control sequence satisfies some restrictions.

The above convergence theorems are weak. In this paper, motivated by the above results, we consider the problem of finding a common solution to the zero point problems and fixed point problems based on hybrid iterative methods with errors. Strong convergence theorems are established in the framework of Hilbert spaces.

To obtain our main results in this paper, we need the following lemmas and definitions. Let $C$ be a nonempty, closed, and convex subset of $H$. Let $S: C \rightarrow C$ be a mapping. Then the mapping $I-S$ is demiclosed at zero, that is, if $\left\{x_{n}\right\}$ is a sequence in $C$ such that $x_{n}-\bar{x}$ and $x_{n}-S x_{n} \rightarrow 0$, then $\bar{x} \in F(S)$.

Lemma [9] Let $C$ be a nonempty, closed, and convex subset of $H, A: C \rightarrow H$ be a mapping, and $B: H \rightrightarrows H$ be a maximal monotone operator. Then $F\left(J_{r}(I-\lambda A)\right)=(A+B)^{-1}(0)$.

\section{Main results}

Theorem 2.1 Let $C$ be a nonempty closed convex subset of a real Hilbert space $H, A$ : $C \rightarrow H$ be an $\alpha$-inverse-strongly monotone mapping, $S: C \rightarrow C$ be a quasi-nonexpansive mapping such that $I-S$ is demiclosed at zero, and $B$ be a maximal monotone operator on $H$ such that the domain of $B$ is included in $C$. Assume that $\mathcal{F}=F(S) \cap(A+B)^{-1}(0) \neq \emptyset$. Let $\left\{\lambda_{n}\right\}$ be a positive real number sequence. Let $\left\{\alpha_{n}\right\}$ be a real number sequence in $[0,1]$. Let $\left\{x_{n}\right\}$ be a sequence in $C$ generated in the following iterative process:

$$
\left\{\begin{array}{l}
x_{1} \in C, \\
C_{1}=C, \\
y_{n}=\alpha_{n} x_{n}+\left(1-\alpha_{n}\right) S J_{\lambda_{n}}\left(x_{n}-\lambda_{n} A x_{n}\right), \\
C_{n+1}=\left\{z \in C_{n}:\left\|y_{n}-z\right\| \leq\left\|x_{n}-z\right\|\right\}, \\
x_{n+1}=P_{C_{n+1}} x_{1}, \quad n \geq 1,
\end{array}\right.
$$


where $J_{\lambda_{n}}=\left(I+\lambda_{n} B\right)^{-1}$. Suppose that the sequences $\left\{\alpha_{n}\right\}$ and $\left\{\lambda_{n}\right\}$ satisfy the following restrictions:

(a) $0 \leq \alpha_{n} \leq a<1$

(b) $0<b \leq \lambda_{n} \leq c<2 \alpha$.

Then the sequence $\left\{x_{n}\right\}$ converges strongly to $P_{\mathcal{F}} x_{1}$.

Proof First, we show that $C_{n}$ is closed and convex. Notice that $C_{1}=C$ is closed and convex. Suppose that $C_{i}$ is closed and convex for some $i \geq 1$. We show that $C_{i+1}$ is closed and convex for the same $i$. Indeed, for any $v \in C_{i}$, we see that

$$
\left\|y_{i}-z\right\| \leq\left\|x_{i}-z\right\|
$$

is equivalent to

$$
\left\|y_{i}\right\|^{2}-\left\|x_{i}\right\|^{2}-2\left\langle z, y_{i}-x_{i}\right\rangle \geq 0 .
$$

Thus $C_{i+1}$ is closed and convex. This shows that $C_{n}$ is closed and convex.

Next, we prove that $I-\lambda_{n} A$ is a nonexpansive mapping. Indeed, we have

$$
\begin{aligned}
& \left\|\left(I-\lambda_{n} A\right) x-\left(I-\lambda_{n} A\right) y\right\|^{2} \\
& \quad=\left\|(x-y)-\lambda_{n}(A x-A y)\right\|^{2} \\
& \quad=\|x-y\|^{2}-2 \lambda_{n}\langle x-y, A x-A y\rangle+\lambda_{n}{ }^{2}\|A x-A y\|^{2} \\
& \quad \leq\|x-y\|^{2}-\lambda_{n}\left(2 \alpha-\lambda_{n}\right)\|A x-A y\|^{2} .
\end{aligned}
$$

In view of the restriction (b), we obtain that $I-\lambda_{n} A$ is nonexpansive. Next, we show that $\mathcal{F} \subset C_{n}$ for each $n \geq 1$. From the assumption, we see that $\mathcal{F} \subset C=C_{1}$. Assume that $\mathcal{F} \subset C_{i}$ for some $i \geq 1$. For any $z \in \mathcal{F} \subset C_{i}$, we find from Lemma that

$$
z=S z=J_{\lambda_{i}}\left(z-\lambda_{i} A z\right)
$$

Put $z_{n}=J_{\lambda_{n}}\left(x_{n}-\lambda_{n} A x_{n}\right)$. Since $J_{\lambda_{n}}$ and $I-\lambda_{n} A$ are nonexpansive, we have

$$
\begin{aligned}
\left\|z_{n}-p\right\| & \leq\left\|\left(x_{n}-\lambda_{n} A x_{n}\right)-\left(p-\lambda_{n} A p\right)\right\| \\
& \leq\left\|x_{n}-p\right\| .
\end{aligned}
$$

It follows from (2.1) that

$$
\begin{aligned}
\left\|y_{i}-z\right\| & =\left\|\alpha_{i} x_{i}+\left(1-\alpha_{i}\right) S z_{i}-z\right\| \\
& \leq \alpha_{i}\left\|x_{i}-z\right\|+\left(1-\alpha_{i}\right)\left\|z_{i}-z\right\| \\
& \leq\left\|x_{i}-z\right\| .
\end{aligned}
$$

This shows that $z \in C_{i+1}$. This proves that $\mathcal{F} \subset C_{n}$. Notice that $x_{n}=P_{C_{n}} x_{1}$. For every $z \in$ $\mathcal{F} \subset C_{n}$, we have

$$
\left\|x_{1}-x_{n}\right\| \leq\left\|x_{1}-z\right\|
$$


In particular, we have

$$
\left\|x_{1}-x_{n}\right\| \leq\left\|x_{1}-P_{\mathcal{F}} x_{1}\right\|
$$

This implies that $\left\{x_{n}\right\}$ is bounded. Since $x_{n}=P_{C_{n}} x_{1}$ and $x_{n+1}=P_{C_{n+1}} x_{1} \in C_{n+1} \subset C_{n}$, we arrive at

$$
\begin{aligned}
0 & \leq\left\langle x_{1}-x_{n}, x_{n}-x_{n+1}\right\rangle \\
& \leq-\left\|x_{1}-x_{n}\right\|^{2}+\left\|x_{1}-x_{n}\right\|\left\|x_{1}-x_{n+1}\right\| .
\end{aligned}
$$

It follows that

$$
\left\|x_{n}-x_{1}\right\| \leq\left\|x_{n+1}-x_{1}\right\|
$$

This implies that $\lim _{n \rightarrow \infty}\left\|x_{n}-x_{1}\right\|$ exists. On the other hand, we have

$$
\begin{aligned}
& \left\|x_{n}-x_{n+1}\right\|^{2} \\
& \quad=\left\|x_{n}-x_{1}\right\|^{2}+2\left\langle x_{n}-x_{1}, x_{1}-x_{n+1}\right\rangle+\left\|x_{1}-x_{n+1}\right\|^{2} \\
& \quad=\left\|x_{n}-x_{1}\right\|^{2}-2\left\|x_{n}-x_{1}\right\|^{2}+2\left\langle x_{n}-x_{1}, x_{n}-x_{n+1}\right\rangle+\left\|x_{1}-x_{n+1}\right\|^{2} \\
& \quad \leq\left\|x_{1}-x_{n+1}\right\|^{2}-\left\|x_{n}-x_{1}\right\|^{2} .
\end{aligned}
$$

It follows that

$$
\lim _{n \rightarrow \infty}\left\|x_{n}-x_{n+1}\right\|=0
$$

Notice that $x_{n+1}=P_{C_{n+1}} x_{1} \in C_{n+1}$. It follows that

$$
\left\|y_{n}-x_{n+1}\right\| \leq\left\|x_{n}-x_{n+1}\right\| .
$$

This in turn implies that

$$
\left\|y_{n}-x_{n}\right\| \leq\left\|y_{n}-x_{n+1}\right\|+\left\|x_{n}-x_{n+1}\right\| \leq 2\left\|x_{n}-x_{n+1}\right\| .
$$

In view of (2.2), we obtain that

$$
\lim _{n \rightarrow \infty}\left\|x_{n}-y_{n}\right\|=0 .
$$

On the other hand, we have

$$
\left\|x_{n}-y_{n}\right\|=\left(1-\alpha_{n}\right)\left\|x_{n}-S z_{n}\right\| .
$$

It follows from (2.3) that

$$
\lim _{n \rightarrow \infty}\left\|x_{n}-S z_{n}\right\|=0 .
$$


For any $p \in \mathcal{F}$, we see that

$$
\begin{aligned}
\left\|z_{n}-p\right\|^{2} & =\left\|J_{\lambda_{n}}\left(x_{n}-\lambda_{n} A x_{n}\right)-J_{\lambda_{n}}\left(p-\lambda_{n} A p\right)\right\|^{2} \\
& \leq\left\|x_{n}-p\right\|^{2}-2\left\langle x_{n}-p, A x_{n}-A p\right\rangle+\lambda_{n}^{2}\left\|A x_{n}-A p\right\|^{2} \\
& \leq\left\|x_{n}-p\right\|^{2}-\lambda_{n}\left(2 \alpha-\lambda_{n}\right)\left\|A x_{n}-A p\right\|^{2} .
\end{aligned}
$$

Notice that

$$
\begin{aligned}
\left\|y_{n}-p\right\|^{2} & \leq \alpha_{n}\left\|x_{n}-p\right\|^{2}+\left(1-\alpha_{n}\right)\left\|S z_{n}-p\right\|^{2} \\
& \leq \alpha_{n}\left\|x_{n}-p\right\|^{2}+\left(1-\alpha_{n}\right)\left\|z_{n}-p\right\|^{2} .
\end{aligned}
$$

Substituting (2.5) into (2.6), we see that

$$
\left\|y_{n}-p\right\|^{2} \leq\left\|x_{n}-p\right\|^{2}-\left(1-\alpha_{n}\right) \lambda_{n}\left(2 \alpha-\lambda_{n}\right)\left\|A x_{n}-A p\right\|^{2} \text {. }
$$

It follows that

$$
\begin{aligned}
\left(1-\alpha_{n}\right) \lambda_{n}\left(2 \alpha-\lambda_{n}\right)\left\|A x_{n}-A p\right\|^{2} & \leq\left\|x_{n}-p\right\|^{2}-\left\|y_{n}-p\right\|^{2} \\
& \leq\left(\left\|x_{n}-p\right\|+\left\|y_{n}-p\right\|\right)\left\|x_{n}-y_{n}\right\| .
\end{aligned}
$$

This implies from (2.3) that

$$
\lim _{n \rightarrow \infty}\left\|A x_{n}-A p\right\|=0
$$

On the other hand, we have

$$
\begin{aligned}
\left\|z_{n}-p\right\|^{2}= & \left\|J_{\lambda_{n}}\left(x_{n}-\lambda_{n} A x_{n}\right)-J_{\lambda_{n}}\left(p-\lambda_{n} A p\right)\right\|^{2} \\
\leq & \left\langle\left(x_{n}-\lambda_{n} A x_{n}\right)-\left(p-\lambda_{n} A p\right), z_{n}-p\right\rangle \\
= & \frac{1}{2}\left(\left\|\left(x_{n}-\lambda_{n} A x_{n}\right)-\left(p-\lambda_{n} A p\right)\right\|^{2}+\left\|z_{n}-p\right\|^{2}\right. \\
& \left.-\left\|\left(x_{n}-\lambda_{n} A x_{n}\right)-\left(p-\lambda_{n} A p\right)-\left(z_{n}-p\right)\right\|^{2}\right) \\
\leq & \frac{1}{2}\left(\left\|x_{n}-p\right\|^{2}+\left\|z_{n}-p\right\|^{2}-\left\|x_{n}-z_{n}-\lambda_{n}\left(A x_{n}-A p\right)\right\|^{2}\right) \\
\leq & \frac{1}{2}\left(\left\|x_{n}-p\right\|^{2}+\left\|z_{n}-p\right\|^{2}-\left\|x_{n}-z_{n}\right\|^{2}-\lambda_{n}^{2}\left\|A x_{n}-A p\right\|^{2}\right. \\
& \left.+2 \lambda_{n}\left\|x_{n}-z_{n}\right\|\left\|A x_{n}-A p\right\|\right) \\
\leq & \frac{1}{2}\left(\left\|x_{n}-p\right\|^{2}+\left\|z_{n}-p\right\|^{2}-\left\|x_{n}-z_{n}\right\|^{2}+2 \lambda_{n}\left\|x_{n}-z_{n}\right\|\left\|A x_{n}-A p\right\|\right) .
\end{aligned}
$$

It follows that

$$
\left\|z_{n}-p\right\|^{2} \leq\left\|x_{n}-p\right\|^{2}-\left\|x_{n}-z_{n}\right\|^{2}+2 \lambda_{n}\left\|x_{n}-z_{n}\right\|\left\|A x_{n}-A p\right\| .
$$


Substituting (2.8) into (2.6), we see that

$$
\left\|y_{n}-p\right\|^{2} \leq\left\|x_{n}-p\right\|^{2}-\left(1-\alpha_{n}\right)\left\|x_{n}-z_{n}\right\|^{2}+2\left(1-\alpha_{n}\right) \lambda_{n}\left\|x_{n}-z_{n}\right\|\left\|A x_{n}-A p\right\| .
$$

It follows that

$$
\begin{aligned}
& \left(1-\alpha_{n}\right)\left\|x_{n}-z_{n}\right\|^{2} \\
& \quad \leq\left\|x_{n}-p\right\|^{2}-\left\|y_{n}-p\right\|^{2}+2\left(1-\alpha_{n}\right) \lambda_{n}\left\|x_{n}-z_{n}\right\|\left\|A x_{n}-A p\right\| \\
& \quad \leq\left(\left\|x_{n}-p\right\|+\left\|y_{n}-p\right\|\right)\left\|x_{n}-y_{n}\right\|+2\left(1-\alpha_{n}\right) \lambda_{n}\left\|x_{n}-z_{n}\right\|\left\|A x_{n}-A p\right\| .
\end{aligned}
$$

In view of the restriction (a), we obtain from (2.7) that

$$
\lim _{n \rightarrow \infty}\left\|x_{n}-z_{n}\right\|=0
$$

Since $\left\{x_{n}\right\}$ is bounded, we may assume that there is a subsequence $\left\{x_{n_{i}}\right\}$ of $\left\{x_{n}\right\}$ converging weakly to some point $x^{*}$. It follows from (2.9) that $z_{n_{i}}$ converges weakly to $x^{*}$. Notice that

$$
\left\|S z_{n}-z_{n}\right\| \leq\left\|S z_{n}-x_{n}\right\|+\left\|x_{n}-z_{n}\right\| .
$$

It follows from (2.4) and (2.9) that

$$
\lim _{n \rightarrow \infty}\left\|S z_{n}-z_{n}\right\|=0
$$

In view of the assumption that $S$ is demiclosed at zero, we see that $x^{*} \in F(S)$.

Next, we show that $x^{*} \in(A+B)^{-1}(0)$. Notice that $z_{n}=J_{\lambda_{n}}\left(x_{n}-\lambda_{n} A x_{n}\right)$. This implies that

$$
x_{n}-\lambda_{n} A x_{n} \in\left(I+\lambda_{n} B\right) z_{n} .
$$

That is,

$$
\frac{x_{n}-z_{n}}{\lambda_{n}}-A x_{n} \in B z_{n}
$$

Since $B$ is monotone, we get for any $(u, v) \in B$, that

$$
\left\langle z_{n}-u, \frac{x_{n}-z_{n}}{\lambda_{n}}-A x_{n}-v\right\rangle \geq 0 .
$$

Replacing $n$ by $n_{i}$ and letting $i \rightarrow \infty$, we obtain from (2.10) that

$$
\langle\omega-u,-A \omega-v\rangle \leq 0
$$

This means $-A \omega \in B \omega$, that is, $0 \in(A+B)(\omega)$. Hence, we get $\omega \in(A+B)^{-1}(0)$. This completes the proof that $x^{*} \in \mathcal{F}$.

Notice that $P_{\mathcal{F}} x_{1} \subset C_{n+1}$ and $x_{n+1}=P_{C_{n+1}} x_{1}$, we have

$$
\left\|x_{1}-x_{n+1}\right\| \leq\left\|x_{1}-P_{\mathcal{F}} x_{1}\right\| .
$$


On the other hand, we have

$$
\begin{aligned}
\left\|x_{1}-P_{\mathcal{F}} x_{1}\right\| & \leq\left\|x_{1}-x^{*}\right\| \\
& \leq \liminf _{i \rightarrow \infty}\left\|x_{1}-x_{n_{i}}\right\| \\
& \leq \limsup _{i \rightarrow \infty}\left\|x_{1}-x_{n_{i}}\right\| \\
& \leq\left\|x_{1}-P_{\mathcal{F}} x_{1}\right\| .
\end{aligned}
$$

We, therefore, obtain that

$$
\left\|x_{1}-x^{*}\right\|=\lim _{i \rightarrow \infty}\left\|x_{1}-x_{n_{i}}\right\|=\left\|x_{1}-P_{\mathcal{F}} x_{1}\right\| .
$$

This implies $x_{n_{i}} \rightarrow x^{*}=P_{\mathcal{F}} x_{1}$. Since $\left\{x_{n_{i}}\right\}$ is an arbitrary subsequence of $\left\{x_{n}\right\}$, we obtain that $x_{n} \rightarrow P_{\mathcal{F}} x_{1}$ as $n \rightarrow \infty$. This completes the proof.

From Theorem 2.1, we have the following results immediately.

Corollary 2.2 Let $C$ be a nonempty closed convex subset of a real Hilbert space $H, A: C \rightarrow$ $H$ be an $\alpha$-inverse-strongly monotone mapping, and $B$ be a maximal monotone operator on $H$ such that the domain of $B$ is included in $C$. Assume that $(A+B)^{-1}(0) \neq \emptyset$. Let $\left\{\lambda_{n}\right\}$ be a positive real number sequence. Let $\left\{\alpha_{n}\right\}$ be a real number sequence in $[0,1]$. Let $\left\{x_{n}\right\}$ be a sequence in $C$ generated in the following iterative process:

$$
\left\{\begin{array}{l}
x_{1} \in C, \\
C_{1}=C, \\
y_{n}=\alpha_{n} x_{n}+\left(1-\alpha_{n}\right) J_{\lambda_{n}}\left(x_{n}-\lambda_{n} A x_{n}\right), \\
C_{n+1}=\left\{z \in C_{n}:\left\|y_{n}-z\right\| \leq\left\|x_{n}-z\right\|\right\}, \\
x_{n+1}=P_{C_{n+1}} x_{1}, \quad n \geq 1,
\end{array}\right.
$$

where $J_{\lambda_{n}}=\left(I+\lambda_{n} B\right)^{-1}$. Suppose that the sequences $\left\{\alpha_{n}\right\}$ and $\left\{\lambda_{n}\right\}$ satisfy the following restrictions:

(a) $0 \leq \alpha_{n} \leq a<1$

(b) $0<b \leq \lambda_{n} \leq c<2 \alpha$.

Then the sequence $\left\{x_{n}\right\}$ converges strongly to $P_{(A+B)^{-1}(0)} x_{1}$.

Let $f: H \rightarrow(-\infty, \infty]$ be a proper lower semicontinuous convex function. Define the subdifferential

$$
\partial f(x)=\{z \in H: f(x)+\langle y-x, z\rangle \leq f(y), \forall y \in H\}
$$

for all $x \in H$. Then $\partial f$ is a maximal monotone operator of $H$ into itself; see [23] for more details. Let $C$ be a nonempty closed convex subset of $H$ and $i_{C}$ be the indicator function of $C$, that is,

$$
i_{C} x= \begin{cases}0, & x \in C, \\ \infty, & x \notin C .\end{cases}
$$


Furthermore, we define the normal cone $N_{C}(v)$ of $C$ at $v$ as follows:

$$
N_{C} v=\{z \in H:\langle z, y-v\rangle \leq 0, \forall y \in H\}
$$

for any $v \in C$. Then $i_{C}: H \rightarrow(-\infty, \infty]$ is a proper lower semicontinuous convex function on $H$ and $\partial i_{C}$ is a maximal monotone operator. Let $J_{\lambda} x=\left(I+\lambda \partial i_{C}\right)^{-1} x$ for any $\lambda>0$ and $x \in H$. From $\partial i_{C} x=N_{C} x$ and $x \in C$, we get

$$
\begin{aligned}
v=J_{\lambda} x & \Leftrightarrow \quad x \in v+\lambda N_{C} v \\
& \Leftrightarrow \quad\langle x-v, y-v\rangle \leq 0, \quad \forall y \in C, \\
& \Leftrightarrow \quad v=P_{C} x,
\end{aligned}
$$

where $P_{C}$ is the metric projection from $H$ into $C$. Similarly, we can get that $x \in(A+$ $\left.\partial i_{C}\right)^{-1}(0) \Leftrightarrow x \in V I(A, C)$. Putting $B=\partial i_{C}$ in Theorem 2.1, we can see $J_{\lambda_{n}}=P_{C}$. The following is not hard to derive.

Corollary 2.3 Let $C$ be a nonempty closed convex subset of a real Hilbert space $H, A: C \rightarrow$ $H$ be an $\alpha$-inverse-strongly monotone mapping, and $S: C \rightarrow C$ be a quasi-nonexpansive mapping such that $I-S$ is demiclosed at zero. Assume that $\mathcal{F}=F(S) \cap V I(C, A) \neq \emptyset$. Let $\left\{\lambda_{n}\right\}$ be a positive real number sequence. Let $\left\{\alpha_{n}\right\}$ be a real number sequence in $[0,1]$. Let $\left\{x_{n}\right\}$ be a sequence in $C$ generated in the following iterative process:

$$
\left\{\begin{array}{l}
x_{1} \in C, \\
C_{1}=C, \\
y_{n}=\alpha_{n} x_{n}+\left(1-\alpha_{n}\right) S P_{C}\left(x_{n}-\lambda_{n} A x_{n}\right), \\
C_{n+1}=\left\{z \in C_{n}:\left\|y_{n}-z\right\| \leq\left\|x_{n}-z\right\|\right\}, \\
x_{n+1}=P_{C_{n+1}} x_{1}, \quad n \geq 1 .
\end{array}\right.
$$

Suppose that the sequences $\left\{\alpha_{n}\right\}$ and $\left\{\lambda_{n}\right\}$ satisfy the following restrictions:

(a) $0 \leq \alpha_{n} \leq a<1$;

(b) $0<b \leq \lambda_{n} \leq c<2 \alpha$.

Then the sequence $\left\{x_{n}\right\}$ converges strongly to $P_{\mathcal{F}} x_{1}$.

In view of Corollary 2.3, we have the following corollary on variational inequalities.

Corollary 2.4 Let $C$ be a nonempty closed convex subset of a real Hilbert space $H$ and $A: C \rightarrow H$ be an $\alpha$-inverse-strongly monotone mapping. Assume that $\mathcal{F}=\operatorname{VI}(C, A) \neq \emptyset$. Let $\left\{\lambda_{n}\right\}$ be a positive real number sequence. Let $\left\{\alpha_{n}\right\}$ be a real number sequence in $[0,1]$. Let $\left\{x_{n}\right\}$ be a sequence in $C$ generated in the following iterative process:

$$
\left\{\begin{array}{l}
x_{1} \in C, \\
C_{1}=C, \\
y_{n}=\alpha_{n} x_{n}+\left(1-\alpha_{n}\right) P_{C}\left(x_{n}-\lambda_{n} A x_{n}\right), \\
C_{n+1}=\left\{z \in C_{n}:\left\|y_{n}-z\right\| \leq\left\|x_{n}-z\right\|\right\}, \\
x_{n+1}=P_{C_{n+1}} x_{1}, \quad n \geq 1 .
\end{array}\right.
$$


Suppose that the sequences $\left\{\alpha_{n}\right\}$ and $\left\{\lambda_{n}\right\}$ satisfy the following restrictions:

(a) $0 \leq \alpha_{n} \leq a<1$

(b) $0<b \leq \lambda_{n} \leq c<2 \alpha$.

Then the sequence $\left\{x_{n}\right\}$ converges strongly to $P_{V I(C, A)} x_{1}$.

\section{Competing interests}

The author declares that they have no competing interests.

\section{Acknowledgements}

The author is grateful to the reviewers' suggestions which improved the contents of the article

Received: 20 November 2012 Accepted: 27 December 2012 Published: 14 January 2013

\section{References}

1. Peaceman, $\mathrm{DH}$, Rachford, $\mathrm{HH}$ : The numerical solution of parabolic and elliptic differential equations. J. Soc. Ind. Appl. Math. 3, 28-415 (1995)

2. Douglas, J, Rachford, $\mathrm{HH}$ : On the numerical solution of heat conduction problems in two and three space variables. Trans. Am. Math. Soc. 82, 421-439 (1956)

3. Kellogg, RB: Nonlinear alternating direction algorithm. Math. Comput. 23, 23-28 (1969)

4. Lions, PL, Mercier, B: Splitting algorithms for the sum of two nonlinear operators. SIAM J. Numer. Anal. 16, 964-979 (1979)

5. Qin, X, Kang, Jl, Cho, YJ: On quasi-variational inclusions and asymptotically strict pseudo-contractions. J. Nonlinear Convex Anal. 11, 441-453 (2010)

6. Zhang, M: Iterative algorithms for common elements in fixed point sets and zero point sets with applications. Fixed Point Theory Appl. 2012, 21 (2012)

7. Takahashi, S, Takahashi, W, Toyoda, M: Strong convergence theorems for maximal monotone operators with nonlinear mappings in Hilbert spaces. J. Optim. Theory Appl. 147, 27-41 (2010)

8. Kamimura, S, Takahashi, W: Weak and strong convergence of solutions to accretive operator inclusions and applications. Set-Valued Anal. 8, 361-374 (2010)

9. Aoyama, K, Kimura, Y, Takahashi, W, Toyoda, M: On a strongly nonexpansive sequence in Hilbert spaces. J. Nonlinear Convex Anal. 8, 471-489 (2007)

10. Browder, FE: Nonlinear operators and nonlinear equations of evolution in Banach spaces. Proc. Symp. Pure Math. 18 78-81 (1976)

11. Kamimura, S, Takahashi, W: Approximating solutions of maximal monotone operators in Hilbert spaces. J. Approx Theory 106, 226-240 (2000)

12. Takahashi, W, Toyoda, M: Weak convergence theorems for nonexpansive mappings and monotone mappings. J. Optim. Theory Appl. 118, 417-428 (2003)

13. Ye, J, Huang, J: Strong convergence theorems for fixed point problems and generalized equilibrium problems of three relatively quasi-nonexpansive mappings in Banach spaces. J. Math. Comput. Sci. 1, 1-18 (2011)

14. Cho, SY, Kang, SM: Approximation of fixed points of pseudocontraction semigroups based on a viscosity iterative process. Appl. Math. Lett. 24, 224-228 (2011)

15. Zegeye, $\mathrm{H}$, Shahzad, $\mathrm{N}$ : Strong convergence theorem for a common point of solution of variational inequality and fixed point problem. Adv. Fixed Point Theory 2, 374-397 (2012)

16. Qin, X, Cho, SY, Kang, SM: Strong convergence of shrinking projection methods for quasi- $\boldsymbol{\phi}$-nonexpansive mappings and equilibrium problems. J. Comput. Appl. Math. 234, 750-760 (2010)

17. Lu, H, Wang, Y: Iterative approximation for the common solutions of a infinite variational inequality system for inverse-strongly accretive mappings. J. Math. Comput. Sci. 2(6), 1660-1670 (2012)

18. Husain, S, Gupta, S: A resolvent operator technique for solving generalized system of nonlinear relaxed cocoercive mixed variational inequalities. Adv. Fixed Point Theory 2, 18-28 (2012)

19. Noor, MA, Huang, Z: Some resolvent iterative methods for variational inclusions and nonexpansive mappings. Appl. Math. Comput. 194, 267-275 (2007)

20. Qin, $X$, Cho, YJ, Kang, SM: Convergence theorems of common elements for equilibrium problems and fixed point problems in Banach spaces. J. Comput. Appl. Math. 225, 20-30 (2009)

21. Kim, JK, Tuyen, TM: Regularization proximal point algorithm for finding a common fixed point of a finite family of nonexpansive mappings in Banach spaces. Fixed Point Theory Appl. 2011, 52 (2011)

22. Wei, Z, Shi, G: Convergence of a proximal point algorithm for maximal monotone operators in Hilbert spaces. J. Inequal. Appl. 2012, 137 (2012)

23. Qin, X, Chang, SS, Cho, YJ: Iterative methods for generalized equilibrium problems and fixed point problems with applications. Nonlinear Anal. 11, 2963-2972 (2010)

24. Qin, X, Shang, M, Su, Y: Strong convergence of a general iterative algorithm for equilibrium problems and variational inequality problems. Math. Comput. Model. 48, 1033-1046 (2008)

25. He, XF, Xu, YC, He, Z: Iterative approximation for a zero of accretive operator and fixed points problems in Banach space. Appl. Math. Comput. 217, 4620-4626 (2011)

26. Wu, C, Liu, A: Strong convergence of a hybrid projection iterative algorithm for common solutions of operator equations and of inclusion problems. Fixed Point Theory Appl. 2012, 90 (2012)

27. Qin, X, Su, Y: Approximation of a zero point of accretive operator in Banach spaces. J. Math. Anal. Appl. 329, 415-424 (2007) 
28. Abdel-Salam, HS, Al-Khaled, K: Variational iteration method for solving optimization problems. J. Math. Comput. Sci. 2, 1457-1497 (2012)

29. Qin, X, Cho, SY, Kang, SM: On hybrid projection methods for asymptotically quasi- $\boldsymbol{\phi}$-nonexpansive mappings. Appl. Math. Comput. 215, 3874-3883 (2010)

30. Zegeye, H, Shahzad, N, Alghamdi, M: Strong convergence theorems for a common point of solution of variational inequality, solutions of equilibrium and fixed point problems. Fixed Point Theory Appl. 2012, 119 (2012)

doi:10.1186/1687-1812-2013-11

Cite this article as: Hecai: On solutions of inclusion problems and fixed point problems. Fixed Point Theory and Applications 2013 2013:11.

Submit your manuscript to a SpringerOpen ${ }^{\circ}$ journal and benefit from:

- Convenient online submission

- Rigorous peer review

Immediate publication on acceptance

Open access: articles freely available online

- High visibility within the field

- Retaining the copyright to your article

Submit your next manuscript at $>$ springeropen.com 